\title{
SEMINARIO DE ESTUDIOS GENERALES: UNA APROXIMACIÓN A LA INTEGRACIÓN DE TEORÍAS, RECURSOS Y EXPERIENCIAS EN EL ESPACIO UNIVERSITARIO
}

\section{María Elena Córdoba}

El Instituto Tecnológico de Santo Domingo (INTEC) fue sede durante los días 1 y 2 de agosto de 2013, del segundo Seminario sobre Estudios Generales celebrado en República Dominicana. El mismo fue inaugurado por el rector Dr. Rolando Guzmán y sirvió de escenario para que la Dra. Leandra Tapia, vicerrectora académica, pusiera en circulación el texto titulado Documentos 20 INTEC, el cual es una compilación cuidadosa de las ponencias y reflexiones presentadas en octubre de 2012 en el marco del pasado encuentro denominado: El papel de los estudios generales en las instituciones con fuerte énfasis en la ciencia y la tecnologia.

El Seminario, cuyo tema central giró alrededor de Los Estudios Generales: una aproximación a la integración de teorías, recursos y experiencias, fue un esfuerzo conjunto de INTEC en colaboración con la Red Internacional de Estudios Generales (RIDEG). El mismo concentró a académicos, funcionarios y expertos en educación superior de diversos países de América Latina y el Caribe con el propósito de reflexionar y compartir inquietudes y resultados de proyectos e investigaciones enmarcados en la integración de los Estudios Generales con el proceso enseñanza aprendizaje. 
La inquietud por debatir este tema surgió porque tanto para la RIDEG como para INTEC es fundamental la discusión, producción de conocimientos y divulgación de los retos y dilemas que enfrentan las instituciones en el desarrollo y consolidación de este importante componente curricular. Uno de los asuntos que más ha llamado la atención de los estudiosos de la educación superior es la relación entre las profesiones y los estudios generales. Este sigue siendo un tema de frontera, al que los avances científicos tecnológicos han potenciado aún más.

Durante el transcurso del Seminario se vincularon de forma novedosa la teoría y la práctica, a partir de experiencias y propuestas de integración de los saberes humanísticos con los científicos y estos a su vez con la ingeniería, los negocios y la medicina. Además, se presentaron de un modo puntual los recursos que mejor resultado han venido teniendo docentes e investigadores en y desde los Estudios Generales para fortalecer la formación integral de todo el estudiantado.

La finalidad principal del evento fue servir como espacio propicio para el diálogo sostenido y debate en torno a la integración del conocimiento en la formación profesional y la continuidad entre lo que se aprende, cómo se aprende y lo que implica poner en marcha estos saberes y disposiciones. Todo lo cual dio lugar al análisis referente a las repercusiones de la reflexión continua sobre el quehacer académico, al igual que la importancia de la divulgación de los retos y dilemas en la implementación curricular.

El análisis y la reflexión fueron enriquecidos con los aportes de expositores y participantes que concurrieron al evento, hubo una participación activa conformada por siete instituciones nacionales y cinco invitados internacionales. La presencia de cada actor resultó ser de suma y vital importancia fundamentalmente ya que en estas universidades se han utilizado diversas estructuras organizacionales y paradigmas epistemológicos para implementar 
los Estudios Generales en su currículo, y sus aportaciones al compartir estas experiencias resultaron de gran valor para el fortalecimiento de la concepción curricular y la aportación que a partir de ella hacemos a la sociedad.

Como invitados internacionales, el Seminario se nutrió con las presentaciones del coordinador de la RIDEG, Dr. Waldemiro Vélez y del Dr. Carlos Sánchez, en representación de la Universidad de Puerto Rico (UPR), el Dr. Enrique Mata en representación de la Universidad Nacional de Costa Rica y el Dr. Aníbal Mendoza y Karol Orozco de UNINORTE, Colombia. Los expositores de instituciones educativas locales fueron, por la Universidad Iberoamericana (UNIBE), las doctoras Jacqueline Rodríguez y Orieta Liriano; el Dr. Andrés Mateo por la Universidad APEC (UNAPEC), el Dr. David Álvarez y la Dra. Alina Bello por la Pontificia Universidad Católica Madre y Maestra (PUCMM). Las ponencias de representantes de la universidad anfitriona, estuvieron a cargo de la Lic. Lucero Arboleda de Roa, la Dra. Alba Enríquez y el Lic. Bernardo Echavarría, el Dr. Miguel Suazo, el Mtro. Corides Pérez, el Ing. José Jiménez y la Dra. María Córdoba.

Diferentes análisis, debates y reflexiones se dieron lugar en torno a la integración de teorías, recursos y experiencias, destacándose la importancia de tener una educación con visión holística, en donde se evidencien las interrelaciones de cada disciplina que participa en el entramado curricular. Se subrayaron las deficiencias de los procesos pedagógicos con relación a la vertiginosidad de los cambios y los avances tecnológicos y se plantearon proyecciones en materia educativa a partir de los diferentes marcos presentados.

Al final del seminario se invitó a la reflexión sobre lo teórico y lo pragmático, recalcando y acentuando que no se puede soslayar la existencia de interacción entre los principios teóricos y la práctica educativa. En ese mismo tenor, vale decir que resultó 
significativa la coincidencia y la evidencia de que falta mucho por hacer, por hablar e investigar y compartir entre las comunidades académicas, así como la necesidad de un replanteamiento de las prácticas que se despliegan en la educación superior, para lograr la formación de ciudadanos altamente calificados, con espíritu democrático, visión crítica y comprometidos con el bien común de la sociedad.

El éxito alcanzado en los propósitos que dieron lugar a este evento, motivaron a los participantes para dar continuidad y seguimiento a los temas planteados, así como establecer el compromiso para celebrar otro seminario en el año 2014. 